\title{
The interdecadal worsening of weather conditions affecting aerosol pollution in the Beijing area in relation to climate warming
}

\author{
Xiaoye Zhang ${ }^{1,2}$, Junting Zhong ${ }^{1}$, Jizhi Wang ${ }^{1}$, Yaqiang Wang ${ }^{1}$, and Yanju Liu ${ }^{3}$ \\ ${ }^{1}$ State Key Laboratory of Severe Weather \& Key Laboratory of Atmospheric Chemistry of CMA, \\ Chinese Academy of Meteorological Sciences, Beijing, 100081, China \\ ${ }^{2}$ Center for Excellence in Regional Atmospheric Environment, IUE, CAS, Xiamen, 361021, China \\ ${ }^{3}$ National Climate Centre, China Meteorological Administration, Beijing, 100081, China
}

Correspondence: Xiaoye Zhang (xiaoye@gov.cma.cn)

Received: 9 February 2018 - Discussion started: 16 February 2018

Revised: 15 April 2018 - Accepted: 22 April 2018 - Published: 27 April 2018

\begin{abstract}
The weather conditions affecting aerosol pollution in Beijing and its vicinity (BIV) in wintertime have worsened in recent years, particularly after 2010 . The relation between interdecadal changes in weather conditions and climate warming is uncertain. Here, we analyze long-term variations of an integrated pollution-linked meteorological index (which is approximately and linearly related to aerosol pollution), the extent of changes in vertical temperature differences in the boundary layer (BL) in BIV, and northerly surface winds from Lake Baikal during wintertime to evaluate the potential contribution of climate warming to changes in meteorological conditions directly related to aerosol pollution in this area; this is accomplished using NCEP reanalysis data, surface observations, and long-term vertical balloon sounding observations since 1960 . The weather conditions affecting BIV aerosol pollution are found to have worsened since the $1960 \mathrm{~s}$ as a whole. This worsening is more significant after 2010, with $\mathrm{PM}_{2.5}$ reaching unprecedented high levels in many cities in China, particularly in BIV. The decadal worsening of meteorological conditions in BIV can partly be attributed to climate warming, which is defined by more warming in the higher layers of the boundary layer (BL) than the lower layers. This worsening can also be influenced by the accumulation of aerosol pollution, to a certain extent (particularly after 2010), because the increase in aerosol pollution from the ground leads to surface cooling by aerosol-radiation interactions, which facilitates temperature inversions, increases moisture accumulations, and results in the extra deterioration of meteorological conditions. If analyzed as a linear trend, weather conditions have worsened by
\end{abstract}

$\sim 4 \%$ each year from 2010 to 2017 . Given such a deterioration rate, the worsening of weather conditions may lead to a corresponding amplitude increase in $\mathrm{PM}_{2.5}$ in BIV during wintertime in the next 5 years (i.e., 2018 to 2022). More stringent emission reduction measures will need to be conducted by the government.

\section{Introduction}

Since individuals experienced heavy aerosol pollution episodes (HPEs) in January 2013 in Beijing and its vicinity (BIV) in central-eastern China, changes in aerosol particle concentrations and their chemical components have attracted special attention to high population density areas with rapid economic growth (Huang et al., 2014b; Zhang et al., 2013; Guo et al., 2014; Wang et al., 2014, 2015; Sun et al., 2014). However, these studies were mainly concerned with changes in emission sources and changes in aerosol physio-chemical characterizations. In addition, weather conditions have an important impact on air pollution. Different weather conditions affect atmospheric pollution by changing ventilation efficiency (i.e., winds, boundary layer height, convection, or frontal passages), dry/wet deposition, loss ratios of chemical conversion, natural emissions, background concentrations (Li et al., 2005; Liu et al., 2003; Leibensperger et al., 2008), early morning solar radiation, frontal passage days (Ordonez et al., 2005), surface temperature and relative humidity (Camalier et al., 2007). Specifically, aerosol pollution in Beijing has been possibly affected by southerly/southwesterly sur- 


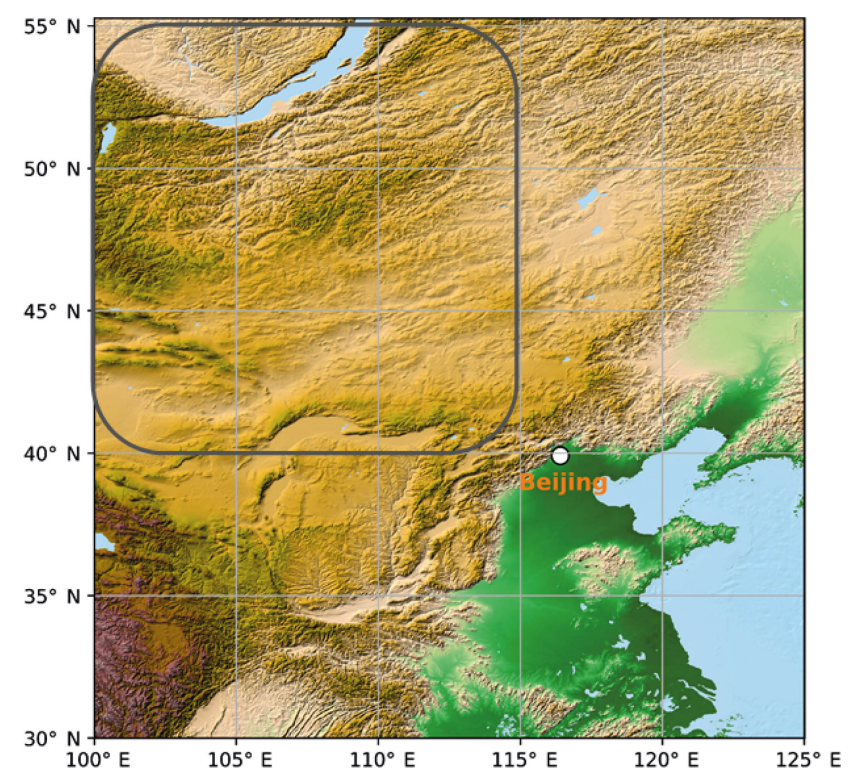

Figure 1. Location of the observational area (Beijing) and the area of the north wind calculated (marked by square).

face winds. Aerosol pollution was also found to become increasingly serious during recent decades (Zhang et al., 2015), which is partially due to increasing emissions in air pollutants from anthropogenic activities (e.g., traffic, industry, and power plants) (Li et al., 2017), but it is also influenced by regional and unfavorable weather conditions (Zhang et al., 2015). Such weather conditions might also be affected by the direct, indirect or semi-direct effects of aerosols, including dust aerosols, whose impact on air quality and weather conditions has been investigated (Shao et al., 2011; Huang et al., 2014a; Chen et al., 2017). Questions have been raised regarding changes in weather conditions that affect HPEs in BIV from a long-term perspective and the effect of climate warming on meteorological factors that aggravate/alleviate aerosol pollution in this area.

Here, we try to find a quantitative link between climate warming and unfavorable weather conditions in BIV from an interdecadal-scale perspective by investigating available surface and upper-air observations of different meteorological factors; this type of study has not been conducted much so far. We use long-term balloon sounding observations, particularly for temperature change in different layers, to analyze the vertical diffusion of conditions and northerly winds from Lake Baikal (which is located in Beijing's cold air upper transport pathway) to measure horizontal diffusion conditions. The location of the observational area (Beijing) and the area of the north wind we calculated are shown in Fig. 1. Since HPEs in BIV usually appear in winter, we focus our research on January data since 1960.

\section{Methods}

An index of meteorological conditions, PLAM (Parameter Linking Air Quality and Meteorological Elements), which is almost linearly related to PM pollution, is used to reveal changes in regional unfavorable weather conditions that affect aerosol pollution in BIV. The formation and accumulation of aerosol pollutants are closely related to various meteorological factors. However, a single factor cannot completely and linearly reflect pollution conditions, and the effect of some factors even counteract or offset one another (Sui et al., 2007; Pang et al., 2009). To describe meteorological conditions that change simultaneously with identical amplitudes for PM mass concentrations during HPEs in winter in BIV, we use one comprehensive meteorological index (PLAM), which mainly indicates regional atmospheric stability and air condensation ability, to reveal changes in regional unfavorable weather conditions that affect heavy pollution in BIV. The PLAM was derived based on the relationship between PM mass concentrations and key meteorological parameters from 2000 to 2007 for various regions in China (Wang et al., 2012, 2013).

It was established as a function of the following parameters:

$\operatorname{PLAM}(F)$ in $f\left(p, t, w, \mathrm{rh}, e, s, c^{\prime}, \ldots\right)$,

where $p, t, w$, rh, $e, s$, and $c^{\prime}$ represent air pressure, air temperature, wind, relative humidity, evaporability, stability, and the effective parameter associated with the contribution of air pollution $\beta\left(c^{\prime}\right)$, respectively. Furthermore, the final PLAM can be attributed to two major separate factors: (1) initial meteorological conditions $\alpha(m)$ associated with atmospheric condensation processes and (2) a dynamic effective parameter associated with the initial contribution of air pollution $\beta\left(c^{\prime}\right)$, which can be expressed as follows:

$\operatorname{PLAM}=\alpha(m) \times \beta\left(c^{\prime}\right)$.

Initial meteorological contribution can be expressed as the variation of wet-equivalent potential temperature $\left(\theta_{\mathrm{e}}\right)$ :

$\alpha(m)=\frac{\mathrm{d} \theta_{\mathrm{e}}}{\mathrm{d} t}=\theta_{\mathrm{e}} \frac{f_{\mathrm{c}}}{C_{p} T}$,

where $C_{p}$ is the heat capacity of air, $T$ is the temperature, and the condensation function $f_{\mathrm{c}}$ is described by

$f_{\mathrm{c}}=\frac{f_{\mathrm{cd}}}{\left[\left(1+\left(L / C_{p}\right)\left(\delta_{q_{\mathrm{s}}} / \delta T\right)\right)_{p}\right]}$,

where $L$ is the latent heat for condensation or evaporation of water vapor, $q_{\mathrm{s}}$ is the specific humidity, and $f_{\mathrm{cd}}$ is the dry 
condensation function as defined below:

$$
\begin{aligned}
& f_{\mathrm{cd}}=\left[\left(\frac{\delta q_{\mathrm{s}}}{\delta P}\right)_{T}+\gamma\left(\frac{\delta q_{\mathrm{s}}}{\delta T}\right)_{p}\right], \\
& \gamma_{p}=\frac{R_{d}}{C_{p}} \frac{T}{P},
\end{aligned}
$$

where $R_{d}$ is the gas constant. The $f_{\mathrm{c}}$ and $\theta_{\mathrm{e}}$ only account for the meteorological contributions to the PM.

In order to quantify the relative impact of weather conditions on air pollution and eliminate the impact of total aerosol concentration change, a ratio of the initial weather conditions to the observed pollution is introduced as the relative dynamic affect parameter $\mu$ :

$\mu=\frac{\alpha(m)}{c^{\prime}}$,

where $c^{\prime}$ represents the initial contribution of air pollution.

To reduce a sharp seasonal variation in meteorological parameters and derive a parameter applicable for a wider range of conditions, an adaptive function $\beta^{\prime}$ is introduced:

$\beta^{\prime}=\frac{(1-\mu)^{i-1}}{\mu}$,

which completes the definition of Eq. (2) for the PLAM (Wang et al., 2012, 2013; Zhang et al., 2009).

This index has been employed to evaluate the contribution of meteorological factors to changes in atmospheric composition and optical properties over Beijing during the 2008 Olympic Games, identify the contribution of specific meteorological factors to a 10-day haze-fog event in 2013 (Zhang et al., 2013), estimate the relative contribution of meteorological factors to changes in aerosol mass concentrations and chemical compositions in different regions of China during winter from 2006 to 2013 (Zhang et al., 2015) and distinguish the feedback effect of meteorological conditions on the explosive increase in $\mathrm{PM}_{2.5}$ mass concentration during accumulation stages in the Beijing area (Zhong et al., 2017; Zhang et al., 2017).

Because weather conditions that affect Beijing simultaneously affect a relatively large area, including Jing-Jin-Ji (i.e., Beijing, Tianjin and Hebei Province) and its adjacent areas (including Shandong and Henan provinces and the Guanzhong Plain) in China (Zhang et al., 2012), we use the PLAM determined by meteorological data from an observatory in Beijing to represent regional unfavorable weather conditions, which are closely related to aerosol pollution in BIV.

HPEs often occur in wintertime; therefore, we compared the average PLAM in winter with the other three seasons from 2013 to 2017 (Fig. 2). It was found that adverse weather conditions in winter are 1.4 to $2 \times$ worse than those in other seasons, which indicates that even if no additional pollution sources were added in winter (e.g., heating), $\mathrm{PM}_{2.5}$ mass concentrations are going to increase by at least 40 to $100 \%$ on average in winter simply from unfavorable weather conditions. Here, we use the PLAM in January to explore changes in meteorological conditions during HPEs in wintertime. Observations from the observatory (54 511) in southern Beijing for 57 years (from 1960 to 2017) were used to calculate the PLAM and analyze its long-term changes.

Vertical temperature anomalies. Atmospheric vertical observations at standard isobaric surfaces were measured twice daily at 08:00 Beijing time (BT) and 20:00 BT; factors measured included winds, temperature and relative humidity $(\mathrm{RH})$ at the observatory (54 511) in the southern part of Beijing in January from 1960 to 2017. Based on the climatological mean temperature in January, which was calculated as the 30-year atmospheric climate basic state (i.e., 19601989), the temperature anomaly $(\delta T)$ from 1960 to 2017 at different pressure layers $(1000-100 \mathrm{hPa})$ was calculated.

Northerly winds from Lake Baikal. Based on the NCEP/NCAR reanalysis data, we defined the mean northerly wind velocity from Lake Baikal in January as an indicator of the effects of winter monsoons on pollution-linked weather conditions in BIV (Fig. 1).

\section{Results and discussion}

Weather conditions linked to aerosol pollution in BIV in wintertime have worsened since the 1960s, and the worsening is more obvious after the 1980s.

Observed January PLAM values in Beijing exhibited an increasing trend from 1960 to 2017; particularly, positive anomalies have occurred since the 1980s, which shows that weather diffusion conditions favoring aerosol pollution in wintertime have strikingly worsened since the 1980s (Fig. 3a). Meanwhile, China's reform and opening up began nearly 40 years of rapid economic growth, with a large amount of energy consumption with coal as the major part. For example, in the year of 1980, China consumed approximately 0.6 billion tons of coal. By 2013, China's total coal consumption was approximately 2.5 billion tons, which is a factor of 4 increase (NBS-China, 2014). Because the PLAM primarily reflects the stability of air masses and the condensation rate of water vapor on aerosol particles, it is linearly related to the PM mass change (Wang et al., 2012, 2013; Zhang et al., 2009). Approximately $20 \%$ of increasing PLAM values since the 1980s, when calculated with a linear trend (Fig. 3a), have been thought to cause an increase in $\mathrm{PM}_{2.5}$ with similar amplitudes; this $20 \%$ change has been considered to be only caused by intensive unfavorable weather. It is no wonder that in the case for continued and increased emissions, when coupled with worsening weather conditions, the upper limit of the environmental capacity in BIV was exceeded in January of 2013; 10 days of severe aerosol pollution first appeared in central-eastern China, with the most serious pollution appearing in BIV. 

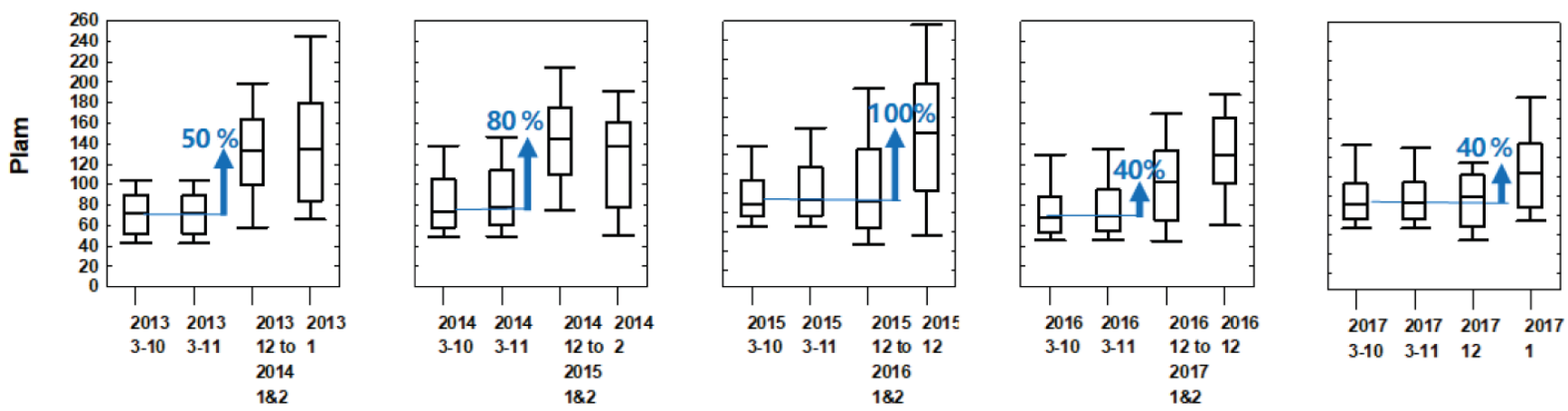

Figure 2. Comparison of the averaged PLAM in winter with the other three seasons from 2013 to 2017 in BIV.

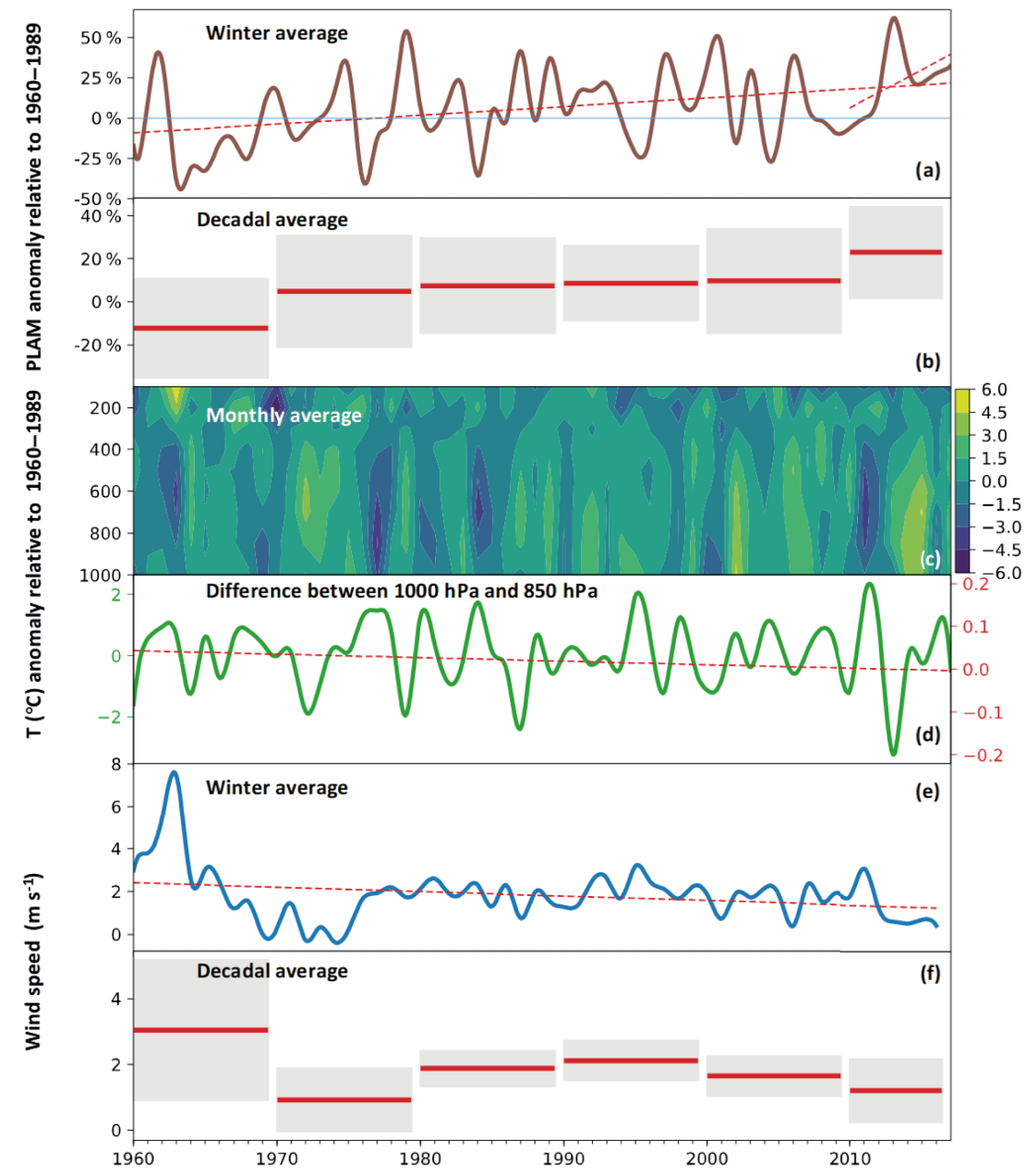

Figure 3. Changes in PLAM, vertical temperature in BIV and northerly wind from Lake Baikal since 1960.

Based on the average interdecadal change in the PLAM during wintertime (Fig. 3b), it can be seen that the PLAM has been increasing since the 1960s. Particularly, in the last 8 years between 2010 and 2017, the mean of PLAM increased more than the growth rate of the mean of each of the previous 10 years, which exhibited more noticeable unfavorable weather conditions. When the $\mathrm{PM}_{2.5}$ mass pollution accu- mulated to a certain extent, it caused the further deterioration of weather conditions, which has been found in almost all HPEs in the Beijing area since 2013 (Zhong et al., 2017, 2018; Zhang et al., 2017). Therefore, we hypothesized that the substantial rise in mean PLAM between 2010 and 2017 should have benefited from the further worsening of meteorological conditions caused by higher $\mathrm{PM}_{2.5}$ mass concentra- 
tions that reached a certain extent. In BIV, aerosol pollution has become increasingly serious during the past decades, particularly since 2010 (Zhang et al., 2015); in January 2013, February 2014, December 2015, and December 2016 to 10 January 2017, 12 persistent HPEs occurred in Beijing, and the mass concentrations of $\mathrm{PM}_{2.5}$ were at historically high levels (Zhong et al., 2018). There will be a detailed discussion on this issue in a later section.

The decadal worsening of meteorological conditions in BIV was partly attributed to climate warming.

Climate warming has a series of consequences. The vertical gradient of atmospheric temperature decreases with the influence of climate warming (Dessler and Davis, 2013; Held and Soden, 2006). The decadal warming is accompanied by increases in mid and upper tropospheric specific humidity. The warmer the atmosphere is, the smaller the temperature gradient is, and the more stable the atmosphere is, the greater the accumulation of air pollution in the surface boundary layer. In this study, it can be seen that the relative upper BL in Beijing is warmer than the lower layer (Fig. 3c-d), which is indicative of the climate warming phenomenon in BIV. By analyzing 49 pollution episodes, Wu et al. (2017) found that the occurrence of pollution accumulation is often caused by the occurrence of high-level convergence layer in the context of climate warming. Weak westerly or northwesterly winds dominate in the mid-upper troposphere and a convergence layer appears between 500 and $700 \mathrm{hPa}$ (Wu et al., 2017), which produce persistent and strong sinking motion in the mid-lower troposphere to reduce the BL height and accumulate pollutants (Wu et al., 2017). As a result of air masses sinking in the mid-lower troposphere, diverging in the lower layers, and being warmed by adiabatic compression, a subsidence inversion appears in the lower layers, which facilitates pollutant accumulation.

In Fig. 3c, we found that the monthly mean temperature anomalies below $200 \mathrm{hPa}$ exhibited warming in some years since 1960 , despite the inter-annual variability. The difference in temperature anomalies between 1000 and $850 \mathrm{hPa}$ decreased throughout the time period since 1960 when described by a linear trend (Fig. 3d), which indicated that temperature differences between the upper and lower boundary layers gradually declined in BIV, resulting in a more stable atmospheric stratification in this region. Because PLAM anomalies gradually became positive after the 1980s (Fig. 3a), temperature anomalies between 1000 and $850 \mathrm{hPa}$ also became negative approximately after the 1980s (Fig. 3d); this shows again that weather conditions after the 1980s, when China's reform and opening up led to the formation of more aerosol pollution, worsened compared to those before the 1980s within the context of climate warming. The correlation coefficient between the monthly mean PLAM and the temperature anomaly difference between 1000 and $850 \mathrm{hPa}$ since the $1980 \mathrm{~s}$ was -0.71 (exceeding the $0.05 \mathrm{sig}$ nificance level) (Fig. 4), which suggests that weather conditions most directly related to pollution in Beijing (PLAM) were indeed closely related to climate warming. With $\sim 0.5$ of the explained variance, one can believe that the contribution of temperature differences due to climate warming to the continued increase in Beijing's PLAM is around $50 \%$ in the month of January since the 1980s.

The decadal worsening of meteorological conditions, especially when aerosol pollution increased to a certain extent after 2010, may also be partly related to aerosol pollution, which induces further worsening of meteorological conditions.

The larger rise in the PLAM mean value between 2010 and 2017 in BIV (Fig. 3b) can be considered to be partly attributed to a vicious cycle in meteorological conditions, which resulted from aerosol pollution increasing to a certain extent. This can also be explained in detail, as an example, in Fig. 5.

We found a surface cooling effect indicated by mean temperature anomalies, which was more striking from 2010 to 2017 relative to that from 1980 to 2017. Aerosol pollution in the BIV region has reached a very serious level since 2010 (Zhang et al., 2015), which was much higher than that in the 1980s. Remarkably, more aerosols back-scattered a larger amount of radiation into space, which caused a significant reduction in radiation reaching the ground. This phenomenon (i.e., when aerosol pollution reaches a certain extent and results in a temperature inversion near the surface layer, which causes more stable atmospheric stratification) was widely found in a large number of HPEs in BIV after 2013 (Zhong et al., 2018).

A feedback loop of climate warming intensifying local unfavorable weather conditions, forming aerosol pollution, and the accumulated aerosol pollution further exacerbating the local unfavorable weather conditions and having a vicious cycle of aerosol pollution, are illustrated in Fig. 6. Climate warming via mid-upper tropospheric-specific humidity increase and air adiabatic sinking causes more upper atmosphere warming relative to the lower one, easily forming unfavorable weather in BIV to form aerosol pollution. During the transport stage (TS) in pollution formation, relatively strong southerly winds prevail in the lower troposphere in BIV, which transports pollutants and water vapor from the south of Beijing to the urban area of Beijing. When the pollution accumulates to a certain extent during the cumulative stage (CS), elevated $\mathrm{PM}_{2.5}$ established by the TS back-scatters amounts of solar radiation to space due to its scattering property, which leads to near-ground radiative cooling. This radiation reduction reduces near-ground temperature to facilitate anomalous inversion, which subsequently suppresses vertical turbulent diffusion and decreases BL height to further trap pollutants and water vapor. Induced by surface cooling, decreased saturation vapor pressure substantially enhances RH. The joint effect of inversion suppression and surface cooling results in appreciable near-ground moisture accumulation, which further accelerates heterogeneous and liquid-phase reactions and enhances aerosol hy- 

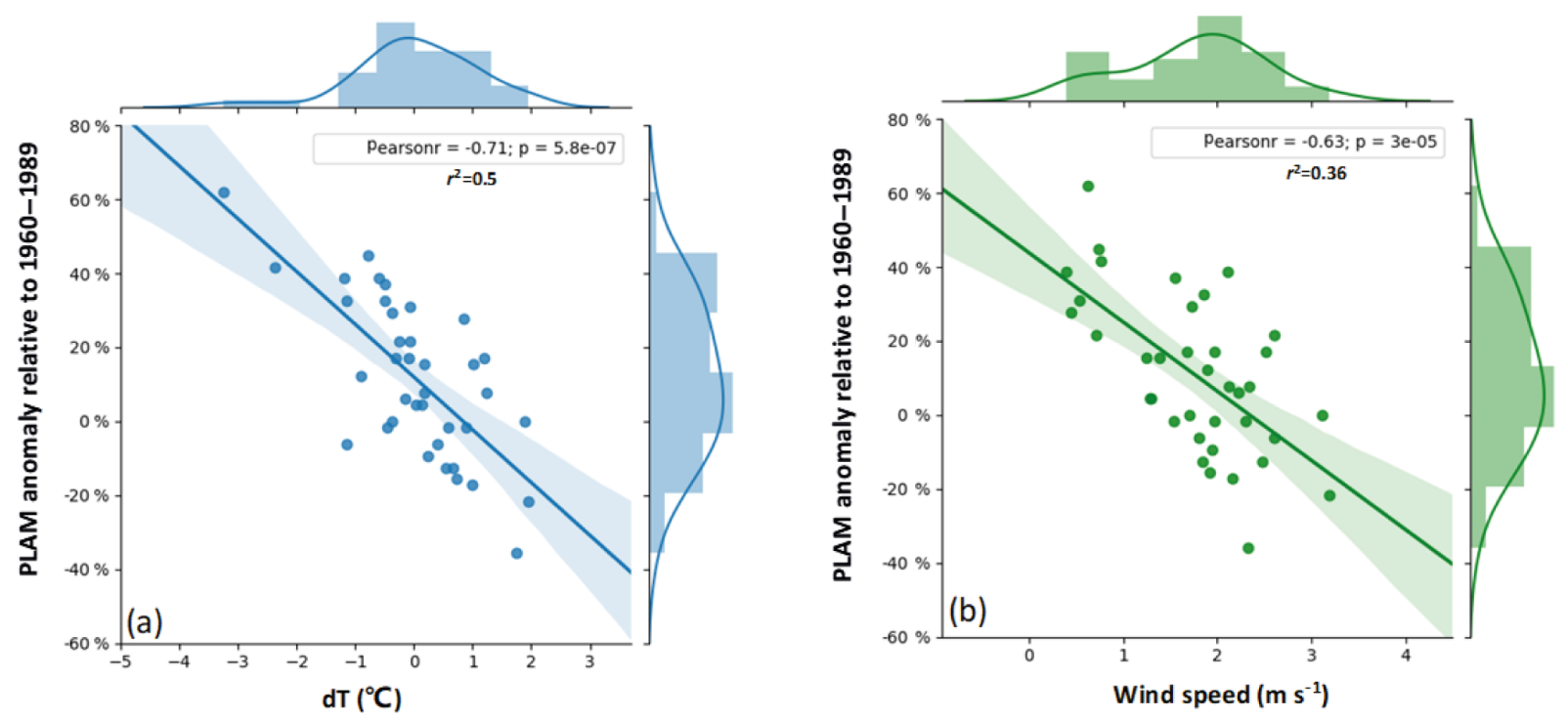

Figure 4. (a) Correlations between the monthly mean PLAM anomalies and the temperature anomaly difference between 1000 and $850 \mathrm{hPa}$ since the 1980s; (b) correlations between the monthly mean PLAM anomalies and wind speed from Lake Baikal since the 1980s.

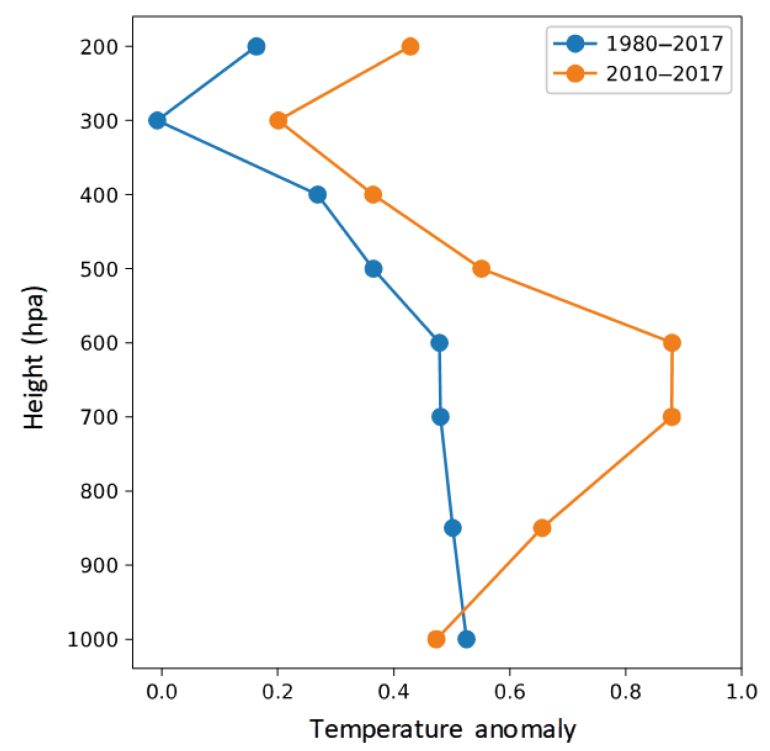

Figure 5. Temperature anomaly vertical profile. Blue denotes the mean temperature anomaly from 1980 to 2017 relative to 1960 to 1989; orange denotes the mean temperature anomaly from 2010 to 2017 relative to 1960 to 1989 ).

groscopic growth to increase $\mathrm{PM}_{2.5}$ mass concentration. The noted positive meteorological feedback dominates $\mathrm{PM}_{2.5}$ explosive growth (Zhong et al., 2017, 2018; Zhang et al., 2017).

The weakening of northerly wind affecting BIV in wintertime also contributed to the continuous deterioration of meteorological conditions in this area.

Wind conditions represent one critical parameter in regulating the cycles of pollution episodes in an area. Strong northerly winds and southerly winds closely correspond to clean periods and pollution episodes in BIV, respectively, because northerly winds (which originate from less populated northern mountainous areas) carry unpolluted air masses, while southerly winds carry polluted air masses from more populated and polluted southern industrial regions (Jia et al., 2008; Guo et al., 2014; Zhong et al., 2018).

Because Lake Baikal is located in the upper transport pathway of northerly winds in winter and is less affected by increasing/decreasing surface roughness in urban areas, the northerly winds from Lake Baikal substantially affect cold air mass movement to the North China Plain, which further affects the formation and elimination of aerosol pollution in BIV (Fig. 3e). We found that monthly mean northerly wind speed from Lake Baikal has declined over the past 57 years, particularly with respect to the past 27 years (i.e., since the 1980s). The mean wind speeds during 1960-1969, 19701979, 1980-1989, 1990-1999, and 2010-2016 are 3.0, 0.92, $1.88,2.11,1.64$, and $1.21 \mathrm{~m} \mathrm{~s}^{-1}$, respectively (Fig. 3f), which indicate that the northerly wind speed has declined gradually as a whole since 1960 . By carrying less cold and dry air over the North China Plain, weakened northerly winds are unfavorable for atmospheric diffusion. Over the past 37 years, the correlation coefficient between northerly wind speed and PLAM is -0.63 (exceeding the 0.05 significance level), which suggests that the year-to-year variability of the northerly wind speed is closely associated with PLAM variability. The number is statistically significant $(p<0.1 \%$ for the correlation coefficient).

For changes in surface wind, Mcvicar et al. (2012) found that a decrease in surface wind was observed in major regions of the world (Mcvicar et al., 2012). Such surface wind trends can be due to increasing surface roughness, the decrease in synoptic weather system intensity and/or changes in mean 


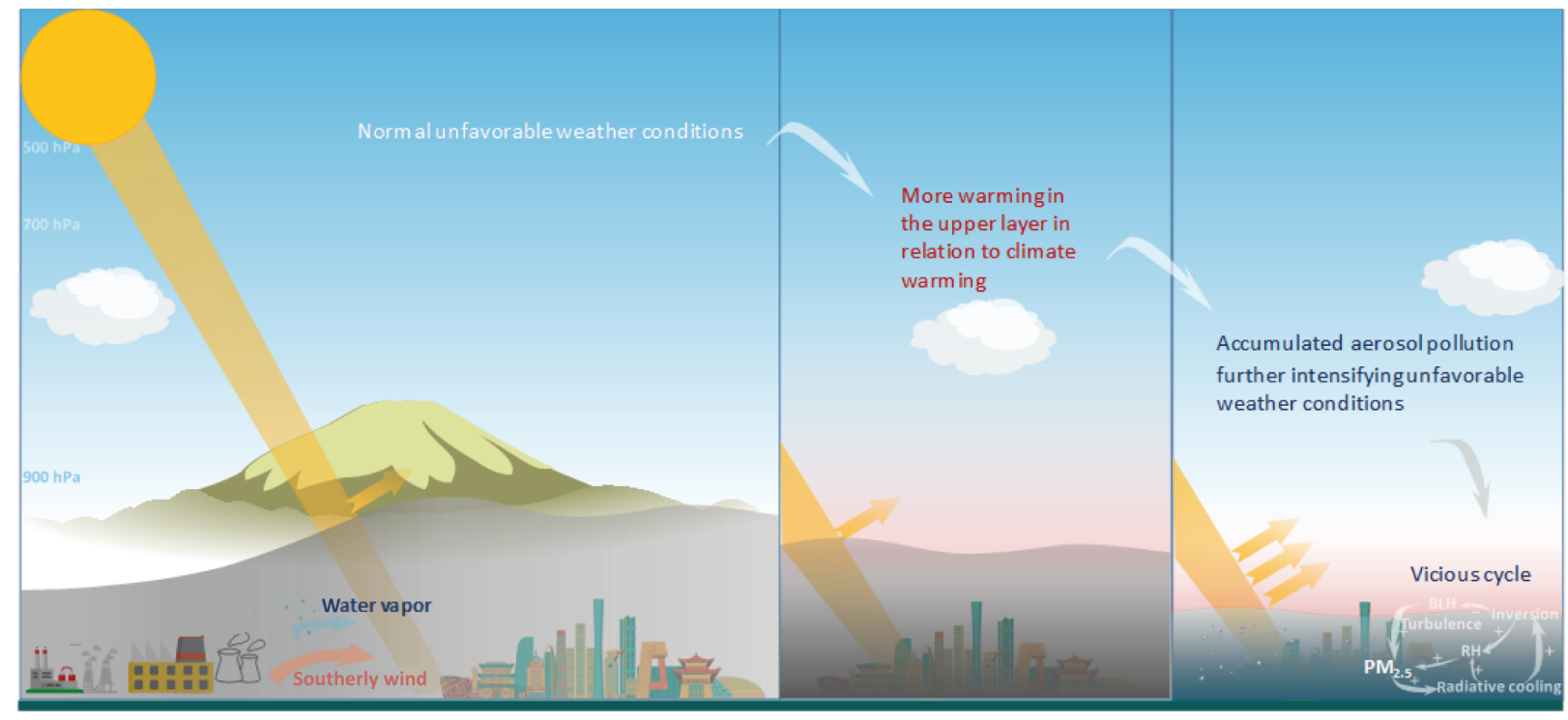

Figure 6. Schematic loop of important feedback for climate warming-unfavorable local and regional weather conditions-forming and accumulating aerosol pollution-further intensifying unfavorable weather conditions-more pollution.

circulation (Vautard et al., 2010). A variety of studies found that surface winds decreased substantially in China (Xu et al., 2006; Guo et al., 2015; Chen et al., 2013). In the urban area of Beijing, the decrease in winds below $300 \mathrm{~m}$ was considered to be partly due to increasing surface roughness caused by land-use change (Liu et al., 2017). However, this reason does not suffice when explaining wind speed changes from Baikal, because the surface roughness of Lake Baikal has not been changed much due to less human activities and industrial construction. The surface wind slowdown from Lake Baikal was likely attributed to changes in atmospheric circulation, which can explain 10 to $50 \%$ of the wind decline in the Northern Hemisphere (Vautard et al., 2010). In addition, the weakening of the East Asian winter monsoon system (Niu et al., 2010) was responsible for the wind slowdown. Both changes in mean circulation and decreases in winter monsoon system intensity are consequences of climate warming.

\section{Conclusions}

Changes in meteorological conditions in winter that are directly related to aerosol pollution in BIV have worsened since the 1960s. Particularly, positive anomalies have occurred since the 1980s, which shows that weather diffusion conditions favoring aerosol pollution in wintertime have strikingly worsened since the 1980s. Meanwhile, China's reform and opening up began nearly 40 years of rapid economic growth, with large amounts of energy consumption mainly deriving from coal. The decadal worsening of meteorological conditions in BIV was partly attributed to climate warming and may also partly be related to the impact on aerosol pollution, which induces further worsening of meteorological conditions when increasing aerosol pollution to a certain extent (particularly after 2010). The impacts of climate change on meteorological conditions that are directly related to aerosol pollution in BIV can also be verified in another aspect: the decrease in wind speed from Lake Baikal in winter. Climate warming, characterized by an increase in warming in the upper atmosphere compared to the low layer in BIV, explained over $50 \%$ of the decadal worsening of weather conditions that are directly related to aerosol pollution in BIV; this includes the part of weather condition worsening caused by the accumulation of aerosol pollution to a certain extent. This worsening is unfavorable for the reduction of $\mathrm{PM}_{2.5}$ mass concentrations in BIV in recent years; it even played a counter role, which probably led to an approximate $4 \%$ increase in $\mathrm{PM}_{2.5}$ mass concentration each year after 2010 when the linear trend from 2010 to 2017 was taken into account. In the future, if the Chinese government aims to maintain a decline in pollution, more effort is needed to offset the adverse effects of climate warming.

Data availability. The underlying research data of this paper can be accessed by contacting the author.

Competing interests. The authors declare that they have no conflict of interest.

Acknowledgements. We are grateful for thoughtful discussion with Yihui Ding. This research is supported by the National Key Project 
of MOST (2016YFC0203306), the Atmospheric Pollution Control of the Prime Minister (DQGG0104), and the Basic Scientific Research Progress of the Chinese Academy of Meteorological Sciences (2017Z011).

Edited by: Jianping Huang

Reviewed by: two anonymous referees

\section{References}

Camalier, L., Cox, W., and Dolwick, P.: The effects of meteorology and their use in assessing ozone trends, Atmos. Environ., 41, 7127-7137, 2007.

Chen, L., Li, D., and Pryor, S. C.: Wind speed trends over China: quantifying the magnitude and assessing causality, Int. J. Climatol., 33, 2579-2590, 2013.

Chen, S. Y., Huang, J. P., Jingxin, L. I., Jia, R., Jiang, N. X., Kang, L. T., Xiaojun, M. A., and Xie, T. T.: Comparison of dust emissions, transport, and deposition between the Taklimakan Desert and Gobi Desert from 2007 to 2011, Science China Earth Sciences, 60, 1-18, 2017.

Dessler, A. E. and Davis, S. M.: Trends in tropospheric humidity from reanalysis systems, J. Geophys. Res.-Atmos., 115, D19127, https://doi.org/10.1029/2010JD014192, 2013.

Guo, H., Xu, M., and Hu, Q.: Changes in near-surface wind speed in China: 1969-2005, Int. J. Climatol., 31, 349-358, 2015.

Guo, S., Hu, M., Zamora, M. L., Peng, J., Shang, D., Zheng, J., Du, Z., Wu, Z., Shao, M., and Zeng, L.: Elucidating severe urban haze formation in China, P. Natl. Acad. Sci. USA, 111, 17373-17378, 2014.

Held, I. M. and Soden, B. J.: Robust Responses of the Hydrological Cycle to Global Warming, J. Climate, 19, 5686-5699, 2006.

Huang, J., Wang, T., Wang, W., Li, Z., and Yan, H.: Climate effects of dust aerosols over East Asian arid and semiarid regions, J. Geophys. Res.-Atmos., 119, 11398-11416, 2014a.

Huang, R.-J., Zhang, Y., Bozzetti, C., Ho, K.-F., Cao, J.-J., Han, Y., Daellenbach, K. R., Slowik, J. G., Platt, S. M., and Canonaco, F.: High secondary aerosol contribution to particulate pollution during haze events in China, Nature, 514, 218-222, $2014 \mathrm{~b}$.

Jia, Y., Rahn, K. A., He, K., Wen, T., and Wang, Y.: A novel technique for quantifying the regional component of urban aerosol solely from its sawtooth cycles, J. Geophys. Res.-Atmos., 113, 6089-6098, 2008.

Leibensperger, E. M., Mickley, L. J., and Jacob, D. J.: Sensitivity of US air quality to mid-latitude cyclone frequency and implications of 1980-2006 climate change, Atmos. Chem. Phys., 8, 7075-7086, https://doi.org/10.5194/acp-8-7075-2008, 2008.

Li, Q., Jacob, D. J., Park, R., Wang, Y., Heald, C. L., Hudman, R., Yantosca, R. M., Martin, R. V., and Evans, M.: North American pollution outflow and the trapping of convectively lifted pollution by upper level anticyclone, J. Geophys. Res.-Atmos., 110, 257266, 2005.

Li, X., Zhang, Q., Zhang, Y., Zhang, L., Wang, Y., Zhang, Q., Li, M., Zheng, Y., Geng, G., and Wallington, T. J.: Attribution of $\mathrm{PM}_{2.5}$ exposure in Beijing-Tianjin-Hebei region to emissions:implication to control strategies, Sci. Bull., 957-964, 2017.

Liu, H., Jacob, D. J., Isabelle, B., Yantosca, R. M., Duncan, B. N., and Sachse, G. W.: Transport pathways for Asian pollution out- flow over the Pacific: Interannual and seasonal variations, J. Geophys. Res.-Atmos., 108, 1445-1459, 2003.

Liu, J., Gao, C. Y., Ren, J., Liang, H., Gao, Z., and Wang, L.: Wind resource potential assessment using a long term tower measurement approach: A case study of Beijing in China, J. Clean. Prod., https://doi.org/10.1016/j.jclepro.2017.10.347, 2017.

Mcvicar, T. R., Roderick, M. L., Donohue, R. J., Li, L. T., Niel, T. G. V., Thomas, A., Grieser, J., Jhajharia, D., Himri, Y., and Mahowald, N. M.: Global review and synthesis of trends in observed terrestrial near-surface wind speeds: Implications for evaporation, J. Hydrol., 416, 182-205, 2012.

NBS-China: China Statistical Yearbook, China Statistics Press, 2014.

Niu, F., Li, Z., Li, C., Kwon-Ho, L., and Wang, M.: Increase of wintertime fog in China: Potential impacts of weakening of the Eastern Asian monsoon circulation and increasing aerosol loading, J. Geophys. Res.-Atmos., 115, 1485-1490, 2010.

Ordóñez, C., Mathis, H., Furger, M., Henne, S., Hüglin, C., Staehelin, J., and Prévôt, A. S. H.: Changes of daily surface ozone maxima in Switzerland in all seasons from 1992 to 2002 and discussion of summer 2003, Atmos. Chem. Phys., 5, 1187-1203, https://doi.org/10.5194/acp-5-1187-2005, 2005.

Pang, X., Mu, Y., Lee, X., Zhang, Y., and Xu, Z.: Influences of characteristic meteorological conditions on atmospheric carbonyls in Beijing, China, Atmos. Res., 93, 913-919, 2009.

Shao, Y., Wyrwoll, K. H., Chappell, A., Huang, J., Lin, Z., Mctainsh, G. H., Mikami, M., Tanaka, T. Y., Wang, X., and Yoon, S.: Dust cycle: An emerging core theme in Earth system science, Aeolian Res., 2, 181-204, 2011.

Sui, K., Wang, Z., Yang, J., Xie, F.-Y., and Zhao, Y.: Beijing Persistent PM10 Pollution and Its Relationship with General Meteorological Features, Research of Environmental Sciences, 20, 77, https://doi.org/10.13198/j.res.2007.06.80.suikk.009, 2007.

Sun, Y., Jiang, Q., Wang, Z., Fu, P., Li, J., Yang, T., and Yin, Y.: Investigation of the sources and evolution processes of severe haze pollution in Beijing in January 2013, J. Geophys. Res.-Atmos., 119, 4380-4398, 2014.

Vautard, R., Cattiaux, J., Yiou, P., Thépaut, J.-N., and Ciais, P.: Northern Hemisphere atmospheric stilling partly attributed to an increase in surface roughness, Nat. Geosci., 3, 756-761, https://doi.org/10.1038/ngeo979, 2010.

Wang, H., An, J., Shen, L., Zhu, B., Pan, C., Liu, Z., Liu, X., Duan, Q., Liu, X., and Wang, Y.: Mechanism for the formation and microphysical characteristics of submicron aerosol during heavy haze pollution episode in the Yangtze River Delta, China, Sci. Total Environ., 490, 501-508, 2014.

Wang, J., Wang, Y., Liu, H., Yang, Y., Zhang, X., Li, Y., Zhang, Y., and Deng, G.: Diagnostic identification of the impact of meteorological conditions on $\mathrm{PM}_{2.5}$ concentrations in Beijing, Atmos. Environ., 81, 158-165, https://doi.org/10.1016/j.atmosenv.2013.08.033, 2013.

Wang, J. Z., Gong, S. L., Zhang, X. Y., Yang, Y. Q., Hou, Q., Zhou, C. H., and Wang, Y. Q.: A Parameterized Method for AirQuality Diagnosis and Its Applications, Adv. Meteorol., 2012, 3181-3190, https://doi.org/10.1155/2012/238589, 2012.

Wang, Y. H., Liu, Z. R., Zhang, J. K., Hu, B., Ji, D. S., Yu, Y. C., and Wang, Y. S.: Aerosol physicochemical properties and implications for visibility during an intense haze episode dur- 
ing winter in Beijing, Atmos. Chem. Phys., 15, 3205-3215, https://doi.org/10.5194/acp-15-3205-2015, 2015.

Wu, P., Ding, Y., and Liu, Y.: Atmospheric circulation and dynamic mechanism for persistent haze events in the Beijing-Tianjin-Hebei region, Adv. Atmos. Sci., 34, 429440, https://doi.org/10.1007/s00376-016-6158-z, 2017.

Xu, M., Chang, C. P., Fu, C., Qi, Y., Robock, A., Robinson, D., and Zhang, H. M.: Steady decline of east Asian monsoon winds, 1969-2000: Evidence from direct ground measurements of wind speed, J. Geophys. Res., 111, https://doi.org/10.1029/2006JD007337, 2006.

Zhang, X., Sun, J., Wang, Y., Li, W., Zhang, Q., Wang, W., Quan, J., Cao, G., Wang, J., Yang, Y., and Zhang, Y.: Factors contributing to haze and fog in China, Chinese Sci. Bull., 58, 1178, https://doi.org/10.1360/972013-150, 2013.

Zhang, X. Y., Wang, Y. Q., Lin, W. L., Zhang, Y. M., Zhang, X. C., Gong, S., Zhao, P., Yang, Y. Q., Wang, J. Z., and Hou, Q.: Changes of Atmospheric Composition and Optical Properties Over BEIJING - 2008 Olympic Monitoring Campaign, B. Am. Meteorol. Soc., 90, 1633-1651, 2009.

Zhang, X. Y., Wang, Y. Q., Niu, T., Zhang, X. C., Gong, S. L., Zhang, Y. M., and Sun, J. Y.: Atmospheric aerosol compositions in China: spatial/temporal variability, chemical signature, regional haze distribution and comparisons with global aerosols, Atmos. Chem. Phys., 12, 779-799, https://doi.org/10.5194/acp12-779-2012, 2012.
Zhang, X. Y., Wang, J. Z., Wang, Y. Q., Liu, H. L., Sun, J. Y., and Zhang, Y. M.: Changes in chemical components of aerosol particles in different haze regions in China from 2006 to 2013 and contribution of meteorological factors, Atmos. Chem. Phys., 15, 12935-12952, https://doi.org/10.5194/acp-15-129352015, 2015.

Zhang, Z., Zhang, X., Zhang, Y., Wang, Y., Zhou, H., Shen, X., Che, H., Sun, J., and Zhang, L.: Characteristics of chemical composition and role of meteorological factors during heavy aerosol pollution episodes in northern Beijing area in autumn and winter of 2015, Tellus B, 69, 1347484, https://doi.org/10.1080/16000889.2017.1347484, 2017.

Zhong, J., Zhang, X., Wang, Y., Sun, J., Zhang, Y., Wang, J., Tan, K., Shen, X., Che, H., and Zhang, L.: Relative contributions of boundary-layer meteorological factors to the explosive growth of PM 2.5 during the red-alert heavy pollution episodes in Beijing in December 2016, J Meteorol. Res., 31, 809-819, 2017.

Zhong, J., Zhang, X., Dong, Y., Wang, Y., Liu, C., Wang, J., Zhang, Y., and Che, H.: Feedback effects of boundary-layer meteorological factors on cumulative explosive growth of $\mathrm{PM}_{2.5}$ during winter heavy pollution episodes in Beijing from 2013 to 2016, Atmos. Chem. Phys., 18, 247-258, https://doi.org/10.5194/acp18-247-2018, 2018. 